\title{
Would 'Good' Values Yield Good 'Value'? Positioning Higher Education in an Emerging Knowledge Economy
}

\author{
Lucienne Abrahams • Patrick FitzGerald
}

Received: 30 November 2011 / Accepted: 20 September 2012 /

Published online: 9 October 2012

(C) The Author(s) 2012. This article is published with open access at Springerlink.com

\begin{abstract}
The values and the value of higher education are equally contested issues in contemporary South Africa. The affirmation of the 'utility' or 'market value' of higher education (Etzkowitz 2002), especially in the context of an emerging network knowledge economy (Castells 1996), is sometimes seen as threatening to traditional higher education values of 'reason and culture' (Barnett 2000). These values are considered to be a bulwark against trends of instrumentalism, populism, managerialism and performativity, currently influencing calls for the re-positioning of higher education. This paper poses the question: Would good values advance the value of higher education in facilitating social and economic progress, beyond instrumentalism, in the context of an emerging knowledge economy? Good values or 'intellectual virtues' (Aristotle) are seen on a continuum from civic-mindedness to institutional self-interest in the spheres of university leadership and governance. The value of higher education is considered in relation to 'the object of life' (Aristotle), which is presented in South African terms. The theoretical framework is informed by selected perspectives on universities in the knowledge economy context, including issues pertaining to national systems of innovation, the triple helix of university-government-industry and theory on the role of universities in development. The subject of the study is a research-active university in an emerging economy. It is argued that the value of higher education in a knowledge economy is not by definition antithetical to traditional values, but may be developed and derived from them in either an evolutionary or revolutionary way.
\end{abstract}

An earlier draft of this paper was presented at the Society for Research on Higher Education (SRHE) conference, Liverpool, UK, December 2008.

L. Abrahams $(\bowtie)$

LINK Centre, Faculty of Humanities, University of the Witwatersrand, PO Box 601, Wits, Johannesburg 2050, South Africa

e-mail: luciennesa@gmail.com

P. FitzGerald

University of the Witwatersrand, Private Bag 3, Wits, Johannesburg 2050, South Africa 
Keywords Universities · Aristotelian logic $\cdot$ Values $\cdot$ Value $\cdot$ Emerging knowledge economy

\section{Introductory Problematic and Perspective}

The values and the value of higher education are equally contested issues in contemporary South Africa. The affirmation of the 'utility' or 'market value' of higher education [14], especially in the context of an emerging network knowledge economy [6], is sometimes seen as threatening to traditional higher education values of 'reason and culture' [5]. These values of reason and culture are considered by many 'guardians' of university values to be a bulwark against trends of instrumentalism, populism, managerialism, performativity and state capture, currently influential in the repositioning of higher education. This paper poses the heuristic question: Would good values realize the value of higher education in facilitating social and economic progress, beyond instrumentalism, in the context of an emerging knowledge economy? To explore this question, three case studies are investigated in a single university setting.

The value of the particular contribution of universities to South African challenges of economic and social development is the subject of some, albeit limited, debate. Badat, a South African vice-chancellor and notable guardian of university values, states 'An instrumental approach to higher education which reduces its value to its efficacy for economic growth, and calls that higher education should comprise of largely professional, vocational and career-focused qualifications and programmes... is to denude it of its considerably wider social value and functions' ([3], p. 13) and later 'The rise of an economy in which knowledge increasingly plays a critical role and is prized for the economic advantage that it can confer on businesses and countries means that knowledge production and the development and application of knowledge takes on a new significance.... Universities clearly take on great importance in this context' ([2], p. 8). Thus, Badat poses for us both sides of the debate.

South Africa is a recently democratic (1994), middle-income country with challenges of unemployment, poverty and inequality. It is also a country in which the economy is increasingly based on the infusion of ever greater knowledge intensity in production, in services and in societal design. The higher education system is a significant contributor to the growing knowledge intensity. However, there is no general agreement, or even consistent discourse, on the nature of the interconnections between universities and the broader economy and society. The received values associated with higher education are classical, 'pre-knowledge economy' values and are generally not conceived of in terms of their articulation to value in a knowledge economy paradigm.

The authors have been participant-observers in the debate on higher education for the past decade. The discussion in the university sector regarding the appropriate level of engagement of universities in societal and economic affairs is of longstanding vintage. During the long night of the apartheid era, one group of universities, which serviced government's intellectual and research needs, was labelled as collaborators in a system of crimes against humanity. Another, known as the 'liberal universities' stood back from close relations with government, but co-operated 
closely with broad sections of business. Inside these 'liberal' universities, internal debates raged as to the extent to which such institutions should be involved with political, community and worker struggles for human rights and democracy [18].

The legacy of this period, after the achievement of a democratic constitution in 1994, was the gradual but steady coming together of the different university groupings, under the banner of academic freedom, which is now guaranteed in the Constitution, section 16(1)(d) [19], and a relatively robust institutional autonomy. Rendered wary by the experiences and memories of the apartheid era and collectively uncertain about the fundamental intentions of new government policies and legislation in regard to the university sector, South African universities, despite occasional bursts of rhetoric with respect to the knowledge economy, have generally remained conservative and cautious in terms of significant institutional or strategic commitments outside of the classical knowledge formats and activities.

As geo-economic regions and individual countries, including South Africa, shift towards knowledge economies of varying types, the discourse on universities in an emerging knowledge economy has remained colourless, dominated by much fiercer debates on equity and redress, institutional mergers, academic freedom and institutional autonomy (see for example $[7,8]$ ) in a system whose knowledge design has remained static since 1994 . There is no doubt that these debates are pertinent in a society characterised by inequality, resource imbalances across universities and a legacy of under-developed university governance. However, South Africa's higher education system must offer value to various actors - students, scientists and academics - as well as the broader society, which is meaningful from the perspective of the heightened demand for knowledge, in order to advance in terms of the size and shape of the economy. By the shape of the economy, we specifically mean the more equitable distribution of wealth and the greater participation in productive activities across the general population, reducing the race, class, gender, urban-rural and knowledge divides.

South Africa exhibits various features of being in transition to a knowledge-based economy. It allocates a reasonable level of gross domestic expenditure on research and development, above $0.9 \%$ throughout the period 2006-2010; it has a wellstructured institutional foundation for human capital advancement and knowledge production, including 23 universities and a wide range of scientific performing agencies; it has relatively sophisticated information and communications technology (ICT) networks and broadband infrastructure for advanced communications, though there is a notable digital divide; and it has adopted a wide range of policies to foster higher education [16] and a national system of innovation [10,11].

A key issue for universities is whether and to what extent they should align themselves with government policy and programmes, given the propensity for the government to deploy an increasing plethora of 'steering mechanisms' in the form of enrolment compacts, continuously reviewed funding frameworks ([16], section 1.5) and national innovation plans [10]. In the decade to 2012, the Department of Science and Technology, the National Advisory Council on Innovation and other organisations have been engaged in promoting and redesigning the national system of innovation, setting strategic science and technology missions for research institutions, including universities.

Within this context, the implication has sharply arisen that government is promoting a one-size-fits-all template to which all members of the system must comply. Some of the 
"steering" has thus appeared as too blunt a tool, creating the tendency for universities to subtly disengage and take refuge in a particular interpretation of traditional academic verities. This set of issues 'crowds out' questions that universities might pose to themselves regarding how they insert themselves into a knowledge-based socioeconomic paradigm, how they might think about change and how they might respond to increased demand for knowledge or initiate new forms of knowledge. Thinking through these issues would enable universities to take their own direction, but with due understanding of other nascent development forces in the socio-economy.

Given the aforesaid, it is necessary to achieve a higher epistemological level of discourse, in order to consider how we can advance from the seeming inertia of a twentieth-century view to a twenty-first-century perspective which sees opportunities to appropriately augment traditional values and to create new value for both university and society. It is generally acknowledged by all actors that the regional socioeconomy benefits from university-based knowledge production. This article seeks to demonstrate that the university also benefits. Each of the case studies demonstrates socio-economic benefits, but the article problematizes the benefit to the university, as this is what is contested in South Africa.

\section{The Relationship of Values to Value}

Aristotle is the first authority to rigorously relate values to value. He develops three important concepts, namely moral virtues as being 'an habitual disposition connected with choice' (Aristotle, II, 6) ([15], p. 54), intellectual virtues as intellectual excellence acquired through practice upon which one reflects and improves and practical wisdom as representing a holistic capacity to add value by doing the right thing sufficiently often.

Moral virtues, in the Aristotelian ethical schema, are never reified absolutes, as in later Kantian moral theory, but are strongly connected to the purpose to which they are being put and to a concomitant 'cool' assessment of context. Intellectual virtues are acquired through cycles of applied practice and appropriate reflection on such experience gained with a view to constant improvement of one's moral surefootedness. Practical wisdom is the holistic outcome of ethical process whereby the ability to link good value to desirable consequences is increasingly embedded and refreshed.

As regards the relationship between values and value, he is thus the first author to thematize the relationship of ethical knowledge to value creation. For Aristotle, good values must create good value or such values have little worth. The activity of developing appropriate value patterns and proclivities must be capable of synergizing good values with palpable value creation in the 'operational' life environment:

Now, if the aim is noble, then cleverness is praiseworthy; if it is base, then cleverness is just unscrupulousness. So we describe both people of practical wisdom and those who are unscrupulous as clever. But practical wisdom is not just cleverness, though it does require cleverness. It is a habitual state which is developed in the eye of the soul only in the sense of moral virtue... (from Aristotle VI, 12, 1144a26-b1) ([15], p. 106). 
Hence, for Aristotle, wisdom capable of linking good values to added value is very different to an isolated ethical decision based on abstract principle, but is rather the constant mapping and verification of a practical terrain. Thus, iterative good practice based on sound values engenders applications appropriate to the given context and therefore is capable of reliably generating value within a multi-dimensional continuum linking enlightened self-interest to civic-mindedness.

With relevance to university leadership and governance, this would relate to the university's 'disposition' to engage in knowledge production that finds its purpose in creating social or economic value. Aristotle's concepts are eminently germane to the knowledge economy discourse due to the greater value and purposes attributed to knowledge as compared to other factors of production within his philosophy, specifically in relation to his specific framing of knowledge, its application and concomitant value.

In considering universities, values and value creation in an 'Aristotelian' knowledge economy paradigm, three further heuristic concepts are mobilized, namely, national systems of innovation, the triple helix of university-industry-government relations and universities in development, each of these being a perspective on knowledge in its relation to economy and society.

A national system of innovation is the loose formation of firms and economic sectors, government policy and funding interventions, universities and research entities, sometimes interconnecting, engaged in creating new knowledge which serves to increase the value of the economy and responsiveness of society. It is conceptualized here as '...a set of institutions whose interactions determine the innovative performance... of national firms' ([17], p. 14), of public services and of social organisations or processes. Higher education expenditure on research and development in South Africa in the 2008/2009 fiscal year was ZAR 4.1 billion or one fifth of the gross R\&D expenditure, where gross expenditure was $0.92 \%$ of GDP ([9], p. 21).

The triple helix model of university-industry-government relations is a form which elucidates that type of research engagement involving the 'capitalization of knowledge'. Its characteristics include the effective utilization of knowledge produced in universities, the growing influence of each strand of the triple helix on the others and the process of firm formation based on intellectual property produced in the university [14].

Universities are technologically engaged institutions, both as users and creators. They may hence be constructed as institutions that are both technologically and socially engaged, since technological innovation is seen as an important source of human development, in areas including public health and environmental management, which 'will also increasingly rely on the generation and application of new knowledge' (United Nations [22], p. 17).

The cogency of applying the Aristotelian argument of values and value to universities in development contexts is encapsulated in the following statement from a United Nations document on innovation for development: 'The linkage between research activities and commercial enterprises continues to be weak in most developing countries. Strengthening this link could help provide fresh stimulus to academic research and re-energize universities' (United Nations [22], p. 136). Accepting that the creation and validation of bodies of knowledge through the utmost academic 
integrity should remain a core value for universities; then universities should also be constantly seeking new horizons for knowledge work in an era where this contribution would be highly valued and would provide visible added value.

\section{Three Studies in Values and Value Creation}

The subject is a research-active university in an emerging economy. The study investigates the extent to which evolving habitual dispositions are capable or not capable of creating value in praxis.

\section{Economic Geology and Mining Exploration}

The Economic Geology Research Institute provides commercially orientated academic research for the mining industry, inter alia in the form of 'industry relevant geological data sets' $[12,24]$. It provides a mechanism for the university to engage in contract work in the field. '...(Institute) is focused on research that seeks to understand the geological genesis of ore bodies, which is a vital piece of understanding needed in regional mineral exploration. There is a natural link between what the Institute does and what the mining industry wants' [12].

The institution values its relationship with the industry as the basis for research funding, student scholarships and access to mines for the purposes of conducting ore body research. This has enabled the institution to gain international recognition in its field. The research generates knowledge about the viability of the mining venture, hence contributes to the 'innovative performance of the firm' and creates economic value - 'you can't open a mine without a great deal of knowledge...... and we provide part of that..... have to do a great deal of exploration which means looking at the economics and the science of it as they are integrated together..... Not routine work,..... it requires intellectual and academic interpretation and model building...' [24].

From a societal change perspective, the "mining industry is changing rapidly... also because mining is seen as a real career opportunity by young South Africans, mostly black and increasingly female, who will change the face of the industry... Geosciences plays a very important role in producing a very high number of high quality black and female honours level graduates who are snapped up by the minerals industry. They have a strong background in economic geology which our tradition and (Institute) greatly contribute towards' [12]. From the perspective of sustaining a 'national system of innovation', increasing the numbers of postgraduates able to contribute to innovation would be effectively creating value.

In research, the university leads with its values of academic integrity, through strict quality control, exclusive oversight of the quality of theses, transparency in contracts and shared intellectual property rights, and if necessary, the institution says 'no'. The concern is expressed that there is a risk of compromise due to salary subventions from industry and the attraction of lucrative consulting: 'I do at times worry about that... sticking to our academic values most definitely creates better value in the long term most clearly expressed in our international reputation' [12]. In this case, value creation is supported by strong values of academic quality and integrity. 
Software Engineering, Globalization and Culture

The software engineering centre promotes the evolution and competitiveness of the software development sector by transferring knowledge from the global context to local students and industry. It is founded as a 'triple helix' partnership of university, municipal government and local information and communications technology (ICT) firms. It offers a pre-incubator facility for software designers, new technologies and new enterprises. It hosts a 'Coachlab' training facility, where mainly black students doing ICT postgraduate degrees participate in leadership development programmes, with coaching from companies. The entrepreneurial academic leader is a university professor of more than 10 years standing who has no desire to relocate to industry.

The values driving the centre relate to the value of creating products that are evocative of a particular society, its way of thinking, behaving and doing business. 'People say why do we need a software industry... software incorporates a whole lot of cultural things, best practice things, ways of doing things that are ours, that are our cultural identity' [13]. In this case, the aim is not to simply emulate the phenomenon of the US or Indian software industries. While international competitiveness is an objective, it is sought as a way of mediating the particular country's cultural identity in the world. 'If we bought all our software from (Y), ..... we become a client to someone else's way of doing things. If your cell phone talks to you in Sotho, you are more engaged in that technology' [13]. Hence, the triple helix works to produce and reproduce local culture embedded in artefacts, containing the possibility of bridging one small element of the 'digital divide'.

As universities remain the pre-eminent, though by no means only, producers of theoretical knowledge, their role in contributing economic value and cultural production remains valid. However, there is resistance to the existence of such a centre at a university, '...if you look at the (institution's) values you find things about engaging in the broader society..... if I talk to Microsoft that's perceived as something you shouldn't do because they're the commercial demon. That stuff devalues what I'm doing against a perceived purity that it's too commercial, too engaged' [13]. Thus, such an engaged role is seen as an important value for a contemporary publicly funded tertiary institution in a knowledge-based economy, but acknowledged as a tension.

\section{The Rural Facility and the Engaged University}

The rural facility creates opportunities for integrated and cross-disciplinary research. It presents a rare and dedicated facility for research opportunities because it hosts such diverse activity. 'It also speaks to the other value, of engagement' [4]. It is the nature of the engagement that is contested.

Between 1999 and 2004, ten research and training programmes were housed at the facility and the Agincourt public health unit continues its association. The university argues that in the early days, the academics suffered an identity crisis-were they an activist non-governmental organisation or a research facility? The research was driven by an 'alternative science' culture aimed at solving problems. However, projects were often ill considered. One project designed cooking equipment which required a bio-digester for fuel. However, the researchers 'never thought through the possibility that that family would take a child out of school to feed the bio-digester, so by the time we got there the child had been out of school for 3 months' [4]. 
Increasingly the research became more 'institutional'. Observer-type research conducted by the Agincourt Health and Population Unit became more prominent, using readily available government data. The number of peer-reviewed journal articles grew exponentially; see Fig. 1. An example of the international value generated is the edition of the Scandinavian Journal of Public Health on "Health, Population and Social Transitions in Rural South Africa" [21] based on longitudinal data collected by a facility-associated project. And cross-disciplinary research began to prosper at the rural facility.

Scepticism regarding poor governance and lack of academic rigour is being replaced by a view of 'enormous opportunities' to speak to the core values of a university, as the facility becomes a place where researchers think of themselves as focused on producing knowledge, thereby making a contribution to local decision-making. The transition required a philosophical approach that understood the blending of knowledge between academic research and community use, leading to a shift in thinking:

'Our job is to give intelligent information to the people who will implement. That then releases us from the professional concerns that I had. We do that on the basis of good quality research, the best expression of the engaged university' [4].

In this third case, values held by pioneering academics led to value in scholarly publishing and availability of indigenous knowledge to local communities. These were not the core values of the university. Nevertheless, they were 'good values' which translated into value through a transition from activism to high-quality research, precisely because researchers were working at the boundaries of their disciplines [20], as is probable in a knowledge economy paradigm.

\section{Conceptual Analysis of Values and Value}

What do the three studies illustrate about values and value creation? How is the relationship between values and value perceived? It would seem to be that, in each case, the academics concerned believed themselves to be operating within the ambit

Fig. 1 Growth in peer-reviewed journal articles and scholarly publications 1992-2010. Source: $[1,23]$

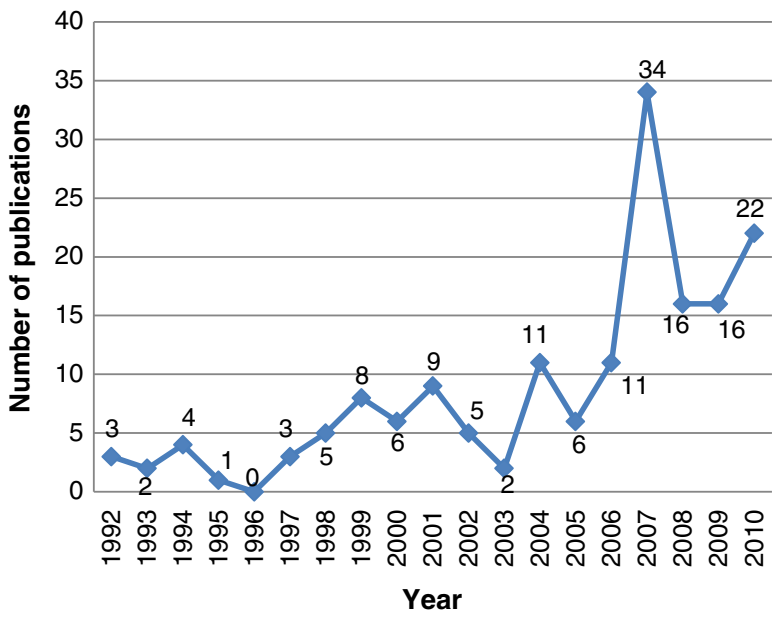


of university core values, reasonably extrapolated to the specificity of the knowledge tasks and challenges being tackled. However, this view would not have seemed entirely axiomatic from a 'guardians of university values' perspective.

Thus, in the case of the geological institute, we observe that the contribution to societal development through research for industry decision-making is underlined by a strong commitment to traditional academic values, while effectively articulating with the knowledge-based economy. Indeed, in this case, academic values appear to direct the nature of the interaction with the mining firms in putting universitygenerated knowledge into another system, while retaining the integrity of the knowledge-generating system. Here, knowledge is configured with academic values, in a way which does not make the knowledge any less valuable to either of the parties. It is an alternative positioning to that in which academics merely hold good values and wait for them to bear results.

Similarly, in the case of the software engineering centre, we observe the university delving into the world of technological culture, economic identity and competitiveness, whilst investigating and theorizing its own research and industry engagement processes. In this case, the university actors are both co-creators of knowledge with industry, supported by local government policy and finance, while simultaneously, the university actors are also potential users of such knowledge which may be integrated into curriculum content. Traditional academic values such as intellectual critique and academic freedom are manifested in the context of an emerging indigenous software industry in South Africa, which would struggle to compete globally without the university's contribution within this knowledge triple helix.

In the rural facility case, we observe academics of the university engaged in supporting community decision-making and interacting with local and provincial government. Based on the success of Agincourt and other independent projects at the rural facility, national government has provided development finance, for this exemplar of rural development research. This programme did not start out from traditional university values, but nevertheless recognized the value of researchbased knowledge. Through its life cycle within the body of the university, the programme internalized many traditional academic values, while also retaining its original values of community-facing innovation and appreciation for the social value of knowledge in a real-world setting. It can be argued that the programme merely adopted the age-old academic values and that it should simply have done so from the outset. The counterargument is that the programme would almost certainly not have come into existence had it not set out from its own chosen starting point. In a knowledge economy context, the starting point need not be the end point, and it is noted that the values of flexibility and risk-taking are important for engendering innovation, these being non-traditional values in higher education.

\section{Evolving a New Epistemology of Higher Education Values and Value}

How does the perceived relationship between values and value affect management, leadership and governance? University leaders are accustomed to knowledge entering society through certain well-established protocols and ensure that there are sufficient protections against instrumentalism, narrow economic interests, censorship, short- 
termism, populism or attacks on academic freedom. However, in the new landscape of knowledge formation, these boundaries have become porous with values and value bleeding across them. The received package of values is no longer a comfort zone, but an arena of tempestuous doubt, open to challenge, negotiation and reorientation. Many of the ventures referred to above are not seamlessly embedded in the university, but are there because of the impact of global knowledge shifts and interpretations of those shifts within the university. They are interesting because they break old paradigms or render them ambiguous. Universities exist in a shifting landscape where abstract values and usable value can both be conceived as 'good values'. The public health project noted four phases of transition, illustrating that the alignment between university values and societal value was not the making of a single moment in time, but the work of 16 years.

Institutional leaders may need to conceptualize the translation of values in the higher education setting into value in economy and society, as set out in Fig. 2, thus raising the game for social engagement to equal status with teaching and research. Values or intellectual virtues, as characterised by Aristotle, can pass through the prism of the higher education institutions' multiple paradigms - institutions operating within a national system of innovation, institutions engaged in the triple helix of university-industry-government relations, institutions gripped in the dynamic of developmental change - to emerge as an array of value or 'practical wisdoms', as envisaged by Aristotle. These practical wisdoms are not essentially instrumentalist, but are more in the nature of integrated knowledge interventions or applications. In the world of higher education change, academic values (academic freedom, research quality and integrity, collegiality, institutional autonomy, intellectual critique) can be

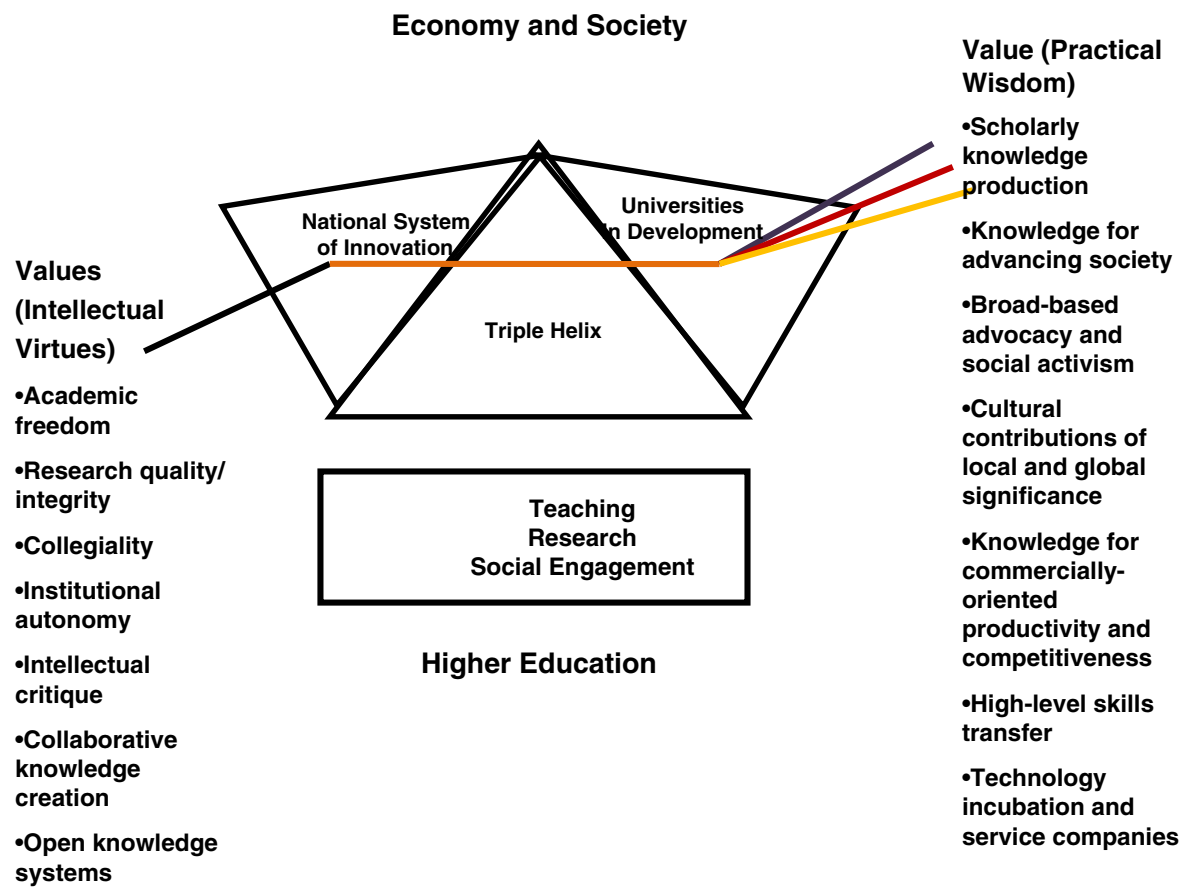

Fig. 2 Conceptual design for translating values to value in higher education 
extended to include new values (collaborative knowledge creation, open knowledge systems) and translated into value for university and society in the form of scholarly knowledge production, knowledge for advancing society, broad-based advocacy and social activism, cultural contributions of local and global significance, knowledge for commercially oriented productivity and competitiveness and high-level skills transfer (Fig. 2). Such values and value can be mutually reinforcing. However, this translation requires strategic leadership and a future-oriented (knowledge economy) discourse.

University leaders seldom intentionally facilitate this constant interface as conceived above, where good values engender worthwhile value in economy and society. Yet, the growing demand for greater knowledge intensity places universities in a position where they can consciously evolve beyond their traditional mission to play an even more powerful role in the future society, becoming virtuous agents of knowledge, rather than mere instruments of knowledge. Furthermore, this cycle of values to value may lead to augmenting traditional values. This article proposes that the activities of socio-economic engagement and innovation be promoted to core values of the university institution and system, as suggested by the case studies.

\section{Concluding Remarks}

Thus, the historically dominant paradigm may no longer be the only valid conceptualization of university values. This study indicates that certain knowledge endeavours living (and sometimes thriving) inside contemporary universities are capable of epistemologically redefining and enriching the traditional 'values' paradigm. Such emerging perspectives on university values include the modalities of redefining culture through research, being a partner in economic innovation and competitiveness, and forging an engaged social consciousness. The national innovation thrust does encourage universities to engage in innovative activity, but in South Africa, this is a largely parallel discussion emanating from outside the universities and not integrated into an immanent hermeneutical conceptualization of the future university.

The value of higher education institutions in a knowledge economy should not be perceived as by definition antithetical to traditional values, but may be developed and derived from them in evolutionary or revolutionary ways. A university environment in which this broader sense of good values is engendered can facilitate 'dispositions' through which iterative applications of practical institutional wisdom will assist in the addition of sustainable value for both society and the university, through discovering and exploring new roles, reach and developmental opportunities. A reluctance to move beyond the traditional values may unintentionally impede advancement beyond their current positioning, by unnecessarily restricting universities' role in the twentyfirst-century knowledge economy.

The key implication for university leadership, governance and management is that it is time to discover, acknowledge and think through a richer and more complex conception of university values and their relation to the value of universities as primary producers of knowledge, and to position universities accordingly. This has multiple consequences directly relevant to high-level strategic planning for the university system, as well as individual institutions, especially in terms of a more sophisticated scanning and analysis of emerging internal and external environments. 
Universities may accordingly seek to develop a structured foresight function that uses well-crafted methodologies and techniques to explore possible futures.

The relevance of the Aristotelian complex of values and value for universities in twenty-first-century knowledge economies is the following: Practical wisdom is precisely the cultivated and iterative translation of good values into societal value, which may be improved through a self-conscious facilitation of new and broader values into the repertoire of the university guardians.

Open Access This article is distributed under the terms of the Creative Commons Attribution License which permits any use, distribution, and reproduction in any medium, provided the original author(s) and the source are credited.

\section{References}

1. Agincourt Unit (2011) Publication statistics. Agincourt Health and Population Unit, University of the Witwatersrand, Johannesburg

2. Badat S (2012) Valuing higher education. Joint Seminar of Higher Education South Africa and the Parliamentary Portfolio Committee on Higher Education and Training, Stellenbosch University: STIAS -Wallenberg Research Centre, 20 April 2012, Stellenbosch

3. Badat S (2008) The trajectory, dynamics, determinants and nature of institutional change in post-1994 South African higher education. Presented at the Higher Education CloseUp 4 conference, Cape Town, June 2008

4. Ballim Y (2008) Interview with Deputy Vice-Chancellor: Academic, University of the Witwatersrand, 13 November 2008

5. Barnett R (2000) Realizing the university in an age of supercomplexity. SRHE and Open University Press, Buckingham \& Philadelphia

6. Castells M (1996) The rise of the network society. Blackwell, Oxford

7. CHE (2009) The state of higher education in South Africa. Higher Education Monitor No. 8, October 2009. Council on Higher Education (CHE), Pretoria

8. Coughlan F, Divala J, Enslin P, Kissack M, Mathebula T (2007) Systemic governance, public accountability and institutional autonomy. In: CHE (ed) Review of higher education in South Africa, selected themes, August 2007. Council on Higher Education (CHE), Pretoria, pp 77-96

9. DST (2010) National survey of research and experimental development 2008/09: high-level key results. Report by Centre for Science, Technology and Innovation Indicators (CESTII), Human Sciences Research Council. Pretoria: Department of Science and Technology (DST), Pretoria. At http://www.dst.gov.za/ publications-policies/r-d-reports/R-D\%20Survey\%20Results\%202008-09\%20Revised.pdf. Accessed 24 October 2011

10. DST (2008) Innovation towards a knowledge-based economy, ten-year plan for South Africa. Department of Science and Technology (DST), Pretoria

11. DST (2002) South Africa's national research and development strategy. Department of Science and Technology (DST), Pretoria

12. Dirks P (2008) Interview with Head of School of Geosciences, University of the Witwatersrand, 7 November 2008

13. Dwolatsky B (2008) Interview with head of Joburg Centre for Software Engineering, 11 November 2008

14. Etzkowitz H (2002) MIT and the rise of entrepreneurial science. Routledge, London

15. Hughes G (2001) Aristotle on ethics. Routledge, London

16. Ministry of Education (2001) The national plan for higher education. Ministry of Education, Pretoria

17. Nelson R, Rosenberg N (1993) Technical innovation and national systems. In: Nelson R (ed) National innovation systems: a comparative analysis. Oxford University Press, New York

18. Perceptions of Wits (1986) Tomorrow begins at Wits today? The role of the university in a changing society. Perceptions of Wits, University of the Witwatersrand, Johannesburg

19. RSA (1996) The Constitution of the Republic of South Africa, Act 108 of 1996. Republic of South Africa (RSA), Pretoria 
20. Tollman S, Kahn, K (2008) Interview with Heads of Agincourt Health and Population Unit. 20 November 2008

21. Tollman S, Kahn K (2007) Health, population and social transitions in South Africa. Scandinavian Journal of Public Health 35(69):4-7, August 2007, Taylor and Francis, UK

22. United Nations (2005) In: Juma C, Lee Y-C (eds) Innovation: applying knowledge in development, UN Millenium Project Task Force on Science, Technology and Innovation. Earthscan, London

23. University of the Witwatersrand (2008) Establishing the Wits Rural Observatory: business case. Report prepared by Mark Burke for the University of the Witwatersrand, Johannesburg, October 2008

24. Wilson A (2008) Interview with Director of Economic Geology Research Institute, University of the Witwatersrand, 17 November 2008 